\title{
LA INFORMACIÓN CONTABLE INDISPENSABLE EN LA TOMA DE DECISIONES
}

\author{
Dr. PASCUAL CHÁVEZ ACKERMANN
}

RESUMEN

En una organización pueden existir varios sistemas de información para propósitos diferentes. La contabilidad es un sistema de información particular, que proporciona información acerca de las consecuencias económicas del proceso de transformación.

Este artículo estudia las características del sistema de información contable. De su lectura, Ud. concluirá que la contabilidad es un sistema para la mediación, síntesis e informe de las consecuencias económicas del proceso de transformación de una empresa. Esta información es empleada para formular y evaluar los contratos que determinan los derechos y responsabilidades de quienes adoptan decisiones.

Los temas que se tratan son:

- Las necesidades de información de quienes adoptan decisiones en el interior y exterior de las organizaciones.

- Funciones principales del sistema de información.

- Componentes de un sistema de información contable.

- Procesamiento de la información de un sistema contable.

Al finalizar el presente estudio, se pretende:
1. Explicar por qué los contratos afectan la necesidad de información acerca de las organizaciones.

2. Explicar cómo los derechos y obligaciones financieras afectan el riesgo y las ganancias.

3. Explicar los efectos de la compensación en las decisiones de los administradores.

4. Identificar el uso de la información contable por los administradores, trabajadores, proveedores, clientes y organizaciones gubernamentales.

5. Señalar el propósito de los principios de contabilidad generalmente aceptados y de la auditoría.

6. Definir la contabilidad financiera.

7. Definir la contabilidad gerencial.

8. Identificar las principales actividades en un sistema de información.

9. Explicar el propósito de un sistema de información gerencial.

10. Explicar el propósito de un sistema de información contable.

11. Identificar las actividades de un sistema de información contable. 
INFORMACIÓN PARA QUIENES ADOPTAN DECISIONES

Como se sabe, el propósito de la contabilidad es proveer información para la adopción de decisiones acerca del proceso de transformación de una empresa. La importancia de la información contable se determina por la forma en que satisface las necesidades de información de quienes la emplean. Dicha información describe las consecuencias económicas del proceso de transformación. Se encarga de medir los recursos financieros empleados para adquirir otros recursos, la conversión en bienes y servicios, y el precio de venta a los clientes.

Objetivo 1.- Explicar por qué los contratos afectan la necesidad de información acerca de las organizaciones.

Las necesidades de información surgen de las numerosas interrelaciones entre los accionistas de una organización: administradores, inversionistas, proveedores, trabajadores, clientes y autoridades gubernamentales. Varios de los mencionados intervienen en el proceso de transformación. Compiten por recursos en los mercados, o los regulan. Intercambian recursos o bienes con una organización, como parte de su proceso de transformación.

\section{Los contratos son acuerdos legales para el intercambio de recursos y servicios. Proveen protección legal a las} partes, si alguno de sus términos no son cumplidos. Los términos de un contrato establecen los derechos y obligaciones de las partes contratantes. Los contratos constituyen acuerdos para "dar y recibir". Cada parte contratante espera recibir algo a cambio de lo que da. Por ejemplo, el contrato de un empleado supone la prestación de un servicio laboral a una compañía a cambio de un sueldo y ciertos beneficios. Los contratos con propietarios y socios se acuerdan entre los dueños, los administradores y otras partes contratantes. Por otro lado, al ser las corporaciones entidades legales, los contratos se acuerdan con la corporación como una de las partes contratantes. Los administradores acuerdan contratos en representación de la corporación y sus dueños.

Los contratos obligan sólo cuando las partes contratantes pueden determinar si sus términos son satisfactorios. Suponga que Ud. y yo firmamos un contrato, por el cual Ud. invierte $\$ 1,000$ en mi empresa y yo me comprometo a pagarle el $10 \%$ de las ganancias cada año. A menos que Ud. cuente con información fidedigna de la empresa, Ud. no podrá saber si yo cumplo con pagarle lo acordado. Por lo tanto, Ud. podrá desistir del contrato. Es necesario que las partes contratantes acepten la información acerca de los contratos como suficiente y confiable para determinarsi sus términos son satisfactorios. La información contable es importante para la formulación y evaluación de los contratos.

La Ilustración $\mathrm{N}^{\circ} 1$ muestra ejemplos de intercambios entre accionistas, para quienes los contratos y la información acerca de las empresas son importantes. La siguiente sección se ocupa de dichos intercambios.

Riesgo y ganancia.- Los contratos identifican los derechos y obligaciones que se acuerdan para establecer el riesgo y las ganancias a compartir entre las partes contratantes. La información acerca del riesgo y las ganancias es importante para determinar los términos del contrato. Se define a la ganancia sobre una inversión como las ganancias obtenidas por una empresa para ser distribuidas entre sus dueños.

El riesgo proviene de la incertidumbre acerca de la suma de las ganancias y del momento en que se perciben. 


\section{ILUSTRACIÓN $\mathbf{N}^{\circ} 1$}

\section{EJEMPLOS DE INTERCAMBIOS SOBRE LOS QUE SE REQUIERE INFORMACIÓN}

La Organización

\begin{tabular}{|c|}
\hline Obtiene Dinero \\
Adquiere \\
Recursos \\
Produce y vende \\
Bienes y servicios \\
\hline
\end{tabular}

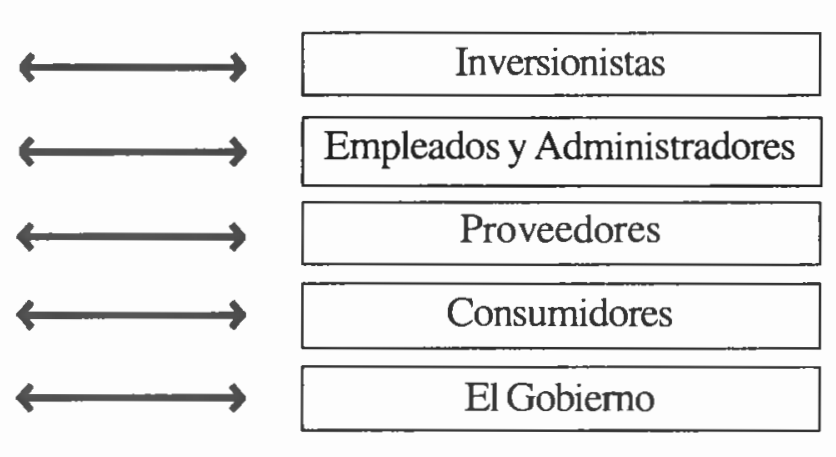

La Ilustración $\mathrm{N}^{\circ} 2$ muestra las ganancias de dos inversiones ( $\mathrm{A}$ y $\mathrm{B}$ ) en varios periodos. ¿Cuál de las dos es más riesgosa? Las ganancias en A son relativamente estables y predecibles; aumentan a una tasa uniforme. Las ganancias en $\mathbf{B}$ son menos predecibles y tienen mayor riesgo que $A$, aunque podrían producir mayores -tilidades en el tiempo que las inversiones en $\mathrm{A}$.

ganancia de los inversionistas de una organización.

También los afectan las decisiones que se adoptan en el exterior. La competencia y las normas gubernamentales influyen en la disponibilidad de recursos empleados en el proceso de transformación, en la demanda por los bienes y servicios y en los precios.

\section{ILUSTRACIÓN No 2}

\begin{tabular}{|ccc|}
\hline \multicolumn{3}{|c|}{ EJEMPLO DE RIESGO Y GANANCIA } \\
\multirow{3}{*}{ Periodo } & \multicolumn{2}{c|}{ Ganancias } \\
\cline { 2 - 3 } & Inversión A & Inversión B \\
1 & & $\$ 10$ \\
2 & $\$ 6$ & 12 \\
3 & 6 & 7 \\
4 & 7 & 3 \\
\hline
\end{tabular}

Las decisiones de los administradores -zerca de las actividades financieras, de mversión y operativas, afectan el riesgo y la
La competencia y la normatividad varían según las empresas y los periodos, debido a las diferentes condiciones del 
mercado, al tipo de productos y procesos de transformación, $y$ a las condiciones políticas y sociales. Por ejemplo, lo concerniente a la seguridad de un producto puede transformar un mercado relativamente estable en otro poco confiable.

Quienes invierten en una empresa esperan obtener ganancias por su inversión. Al mismo tiempo, deben considerar el riesgo de invertir en dicha empresa. ¿Cuánto ganarán si la empresa tiene éxito? ¿Qué sucedería si fracasa? El riesgo y la ganancia están vinculados en la mayoría de las situaciones. Los inversionistas esperan obtener mayores ganancias en inversiones de mayor riesgo. Las mayores ganancias compensan el mayor riesgo, pero las ganancias obtenidas pueden ser diferentes a la previstas. Por ello, las inversiones de mayor riesgo pueden generar ganancias mayores o menores que las de menor riesgo. Sin embargo, las mayores ganancias se asocian a las inversiones de mayor riesgo, 0 de lo contrario los inversionistas no participarian en dichas inversiones. La información contable ayuda a los inversionistas a predecir el riesgo y las ganancias vinculadas a las inversiones.

Las siguientes secciones estudian la evaluación del riesgo y la ganancia que efectúan quienes acuerdan contratos con una organización.

\section{Evaluación de los intercambios}

Objetivo 2.-Explicar cómo la deuda financiera y el capital financiero influyen en el riesgo y la ganancia.

\section{Inversionistas}

Los dueños y los acreedores son inversionistas en una organización. Acuerdan con los administradores la provisión de recursos financieros a cambio de ganancias futuras. Necesitan información para decidir si invierten o no en una empresa y cuándo invertir.

La información contable ayuda a los inversionistas a evaluarel riesgo y la ganancia que podrían esperar por su inversión. También les ayuda a saber si los administradores están cumpliendo los términos de sus contratos.

Las decisiones financieras son la mayor fuente de riesgo en una empresa. La deuda financiera se origina cuando una empresa obtiene recursos financieros de los acreedores. El capital financiero se origina cuando dichos recursos provienen de los dueños. La decisión de emplear deuda financiera o capital financiero influye en el riesgo y la ganancia de una empresa. La obtención de recursos de los acreedores siempre aumenta el riesgo de una empresa, que se ve obligada a pagar intereses a los acreedores y a devolver el monto de la deuda.

Los intereses son la ganancia obtenida por un acreedor. El monto de los intereses no es el principal de la deuda. Los intereses representan la cantidad pagada a un acreedor, además de la devolución del principal. Si una empresa no obtiene suficientes utilidades, no podrá efectuar dichos pagos y los acreedores podrían ocasionar su bancarrota, situación legal por la cual una empresa es controlada por y para los acreedores. Los acreedores también podrían exigir a la empresa liquidar sus recursos para pagar sus deudas.

Caso Típico.- R.H. Macy \& Co se declaró en bancarrota en 1992. Administraba 251 almacenes en USA. En menos de seis años, la administración anterior había adquirido la compañía a los dueños, por lo que asumió grandes deudas. Emplearon el método del endeudamientoo "palanqueo financiero" para 
adquirirla. A comienzos de 1990, la recesión originó la disminución de las utilidades de la compañía que no pudo generar dinero suficiente de sus ventas para pagar los intereses y la deuda principal a su vencimiento. Al final de 1991 y comienzos de 1992, las ganancias de Macy sin deducir intereses e impuestos, disminuyeron a la mitad de las del año anterior. Luego de atender el pago de los intereses, la compañía tuvo una gran pérdida, con pocas probabilidades de recuperación en el futuro inmediato.

Si una empresa se ve forzada a liquidar (a vender todo su capital no circulante); a los acreedores se les paga lo adeudado antes que a los accionistas. Por el contrario, si la empresa es rentable, los accionistas reciben mayores ganancias que los acreedores, porque participan de las utilidades de la empresa. Los acreedores sólo reciben el interés pactado. Por consiguiente, los inversionistas y los administradores eligen entre el riesgo y la ganancia. Suponga que una empresa le debe $\$ 300,000$ a sus acreedores y $\$ 500,000$ a los accionistas. Los acreedores acuerdan un interés del $10 \%$ anual. Considere las siguientes situaciones:
$\$ 500,000)$ y en la Situación 3, fue de (-) $6 \%(-\$ 30,000 / \$ 500,000)$.

Las ganancias de los acreedores tienen menor riesgo que las de los accionistas, pero éstos tienen posibilidad de ganancias mayores o menores en relación a las de los acreedores.

También, con el incremento de la deuda, el riesgo para los accionistas y la empresa, aumenta. Si la empresa tuviera pérdidas; como en la Situación 3 durante varios periodos, no podría pagar la deuda a los acreedores. A mayor deuda pendiente, mayor cantidad de dinero será necesario para efectuar los pagos. Si una empresa no es rentable, tendrá dificultades para generar el dinero que necesita.

\section{Los administradores}

Objetivo 3.- Los efectos de la compensación en las decisiones de los administradores.

Generalmente, los dueños no administran las corporaciones grandes. Para ello, contratan administradores, quienes acuerdan

\begin{tabular}{|c|c|c|c|}
\hline & Situación 1 & Situación 2 & Situación 3 \\
\hline - Ingresos sin deducir intereses & $\$ 100,000$ & $\$ 50,000$ & $\$$ \\
\hline Intereses & 30.000 & 30.000 & 30.000 \\
\hline Ingreso Neto & $\begin{array}{l}\$ 70,000 \\
=======\end{array}$ & $\begin{array}{l}\$ 20,000 \\
========\end{array}$ & $\begin{array}{l}\$ 30,000 \\
========\end{array}$ \\
\hline
\end{tabular}

En la Situación 1, la compañía ganó \$ 100,000. Luego de pagar intereses (sin zonsiderar impuestos), su ingreso neto fue de $\$ 70,000$. Por consiguiente, mientras que as acreedores ganaron el $10 \%$ de interés, os accionistas ganaron el $14 \%(\$ 70,000$ S 500,000). En la Situación 2, los accio-ıstas sólo ganaron el $4 \% \quad(\$ 20,000 /$ prestar dicho servicio a cambio de un sueldo y otras compensaciones. Los dueños, o los directores que los representan, necesitan información para evaluar la actuación de los administradores y compensar su buen desempeño, para locual ofrecen bonificaciones si la empresa obtiene ganancias. La información contable ofrece a los dueños 
y administradores un medio para determinar la compensación que recibirán los administradores.

Los acuerdos de compensación pueden inducir a los administradores a emitir informes que no reflejen fielmente los resultados obtenidos. Como las compensaciones dependen del informe de ingresos y demás informes contables, los administradores podrían presentar cifras que den por resultadoun aumento en sus compensaciones. El control que los administradores tienen sobre la información y la posibilidad de presentar informes que les favorezcan, les ocasiona un dilema ético. Algunas veces, deben optar entre favorecer sus propios intereses o los de la compañía.

Caso Típico.- Suponga que Ud. es el administrador de una compañía. Le pagan un sueldo de $\$ 80,000$ al año y una bonificación del 50\% ( $\$ 40,000)$, siempre y cuando, las utilidades sean superiores de $\$ 500,000$ al año. Ud. trabajó intensamente durante el año y la empresa obtuvo buenos resultados. Sin embargo, Ud. estima que las utilidades sólo llegarán a $\$ 450,000$. La empresa posee acciones de otra compañía por $\$ 100,000$ cuyo valor de mercado asciende a $\$ 200,000$. Vendiendo dichas acciones se podrían obtener un ingreso adicional de $\$ 65,000$ luego de pagar impuestos. La compañía tendría que pagar impuestos adicionales por $\$ 30,000 \mathrm{y}$ $\$ 5,000$ por gastos de venta. Si Ud. vende las acciones, probablemente las podría recomprar, (u otras similares), porque su valor sí habría incrementado. ¿Qué decisión sería la mejor para Ud. como administrador? ¿Cuál sería la mejor decisión para la empresa? ¿Qué haría Ud.?

Objetivo 4.- Identificar el empleo de la información contable por los administradores, empleados, proveedores, clientes y agencias gubernamentales.
Las decisiones de inversión y las de operación tienen efectos diferentes en el riesgo y la ganancia de quienes acuerdan contratos con una compañía. Los administradores deciden qué recursos adquirir, cuándo adquirirlos y cuánto pagar. El valor de los recursos para una empresa depende de su contribución para obtener ganancias.

Toda inversión en recursos implica decisiones sobre el riesgo y la ganancia vinculada a dicha inversión. Una empresa es un conjunto de recursos individuales. La combinación del riesgo y la ganancia de invertir en cada recurso, ayuda a determinar el riesgo y la ganancia de invertir en toda la organización. La administración debe elegir el conjunto de recursos que producirán las ganancias previstas, con un nivel de riesgo aceptable para los dueños y los administradores. Se tiene menor riesgo al invertir en tecnología reconocida y en productos de prestigio que hacerlo en productos $\mathrm{y}$ tecnologías nuevas. La inversión en recursos de algunos países es más riesgosa que invertir en recursos de otros, debido a su situación política y económica. La información contable es útil para identificar el tipo y la ubicación de los recursos de una empresa.

Las actividades operativas transforman los recursos en bienes y servicios. El propósito principal de la contabilidad es medir el costo vinculado al flujo de recursos en el proceso de transformación. También mide los recursos obtenidos de la venta de bienes y servicios. Las ganancias obtenidas de las actividades operativas son las principales determinantes del riesgo y la ganancia. La información acerca del resultado de las actividades operativas se emplea para determinar, comparar y administrar el riesgo y la ganancia de las empresas. 


\section{Los trabajadores}

Los trabajadores tienen un rol determinante en el riesgo y la ganancia de una empresa. Los sueldos y la calidad del trabajo afectan directamente la calidad del producto, las ventas, los costos y las utilidades. Las compañías evalúan el costo y la productividad de sus trabajadores. Comparan su rendimiento con las expectativas de la administración, examinan los cambios en el tiempo y analizan diferentes divisiones entre sí. La información contable ayuda a los administradores a evaluar el rendimiento de los trabajadores.

Los trabajadores negocian por sueldos, beneficios y seguridad en el trabajo. Las compensaciones a los trabajadores son afectadas por el rendimiento y la situación financiera de la empresa. Los sindicatos y otros grupos laborales emplean la información contable para evaluar la capacidad de la compañía en compensar a sus trabajadores. Como la otra parte contratante, los trabajadores evalúan el riesgo y la ganancia de una relación laboral. Si una empresa obtiene buenos resultados, los trabajadores esperan ser recompensados. En caso contrario, podrían enfrentar suspensiones, recorte de beneficios y pérdida del empleo. La información contable ayuda a los trabajadores a evaluar el riesgo y la ganancia de los contratos de trabajo.

\section{Proveedores}

La empresa adquiere materiales, mercancías y otros recursos de los proveedores. Dichos recursos constituyen el costo principal en la mayoría de empresas. Es necesaria una negociación cuidadosa entre los administradores y los proveedores acerca de precios, créditos y programas de entregas. Si la empresa no puede obtener materiales de buena calidad en el momento preciso, puede experimentar pérdidas causadas por la lentitud en la producción, desperdicio, disminución de ventas y la insatisfacción de los clientes. Si un proveedor se retira o no entrega los pedidos, la empresa puede tener dificultades para obtener los recursos necesarios. La información contable ayuda a las empresas a evaluar la capacidad de sus proveedores de satisfacer sus necesidades de recursos.

Los proveedores de recursos, generalmente, venden a crédito por periodos cortos que varían de 30 a 60 días, aunque también se acuerdan plazos mayores. Cuando una empresa se declara en bancarrota, generalmente adeuda grandes sumas a los proveedores, quienes tendrán dificultades para cobrar o no podrán hacerlo. Por consiguiente, los proveedores evalúan el riesgo de vender a crédito a otras empresas. Las condiciones de venta, los precios y los plazos de los pagos son afectadas por la percepción del proveedor del riesgo de dicha venta. Los proveedores emplean la información contable acerca de sus clientes para evaluar el riesgo de que el comprador no pueda pagar por los bienes y servicios que adquiere.

\section{Los clientes}

La empresa abastece a sus clientes. Por lo tanto, los evalúa del mismo modo que es evaluada por los proveedores. Los administradores establecen los términos de venta evaluando el riesgo y la ganancia de dicha venta. Los clientes de mayor riesgo, generalmente obtienen condiciones menos favorables. Por ejemplo, un cliente con buen crédito puede adquirir una casa, un automóvil, artefactos y otros bienes en condiciones más favorables que un cliente con mal crédito.

La decisión del cliente para adquirir productos siempre es afectada por su 
percepción de la calidad y de la manera independiente del precio. Esta decisión también depende del prestigio financiero del vendedor. ¿Se podrá contar con la empresa cuando se necesite mantenimiento, reparación o cambio? ¿Podrá cumplir con las garantías? $¿$ Sus ganancias le permiten invertir en nueva tecnología y mantener la calidad de sus productos? La información contable es empleada para evaluar el riesgo de comprar en determinadas compañías y de vender a ciertos clientes.

Caso Típico.- En 1991, algunas grandes aerolíneas, entre ellas Eastern y Pan American dejaron de operar repentinamente luego de períodos de dificultades financieras. Los aviones fueron inmovilizados y muchos trabajadores fueron despedidos. Gran cantidad de clientes que tenían reservaciones y boletos pagados fueron perjudicados por dichos eventos. Un buen número de clientes potenciales se alejaron de dichas compañías debido a las dificultades financieras durante los primeros meses. La negativa de los clientes potenciales para adquirir boletos en estas aerolíneas generó el problema que condujo a la disolución de dichas empresas.

\section{Agencias gubernamentales}

Las empresas deben obtener autorización para vender bienes y servicios, proporcionar información a las agencias gubernamentales y pagar impuestos sobre sus ventas y sus ganancias. Los gobiernos captan información acerca de las empresas como base para previsión y planificación a nivel local, estadual y nacional. Las empresas deben proporcionar información a las autoridades que regulan las actividades comerciales para asegurar el comercio lícito, trato justo a los trabajadores y la distribución equitativa a los inversionistas.

Las empresas proporcionan infor- mación a autoridades tributarias de diversos niveles. Dicha información es necesaria para establecer los impuestos a las ventas, a la propiedad, a los sueldos y a los ingresos. Los impuestos se determinan de acuerdo al monto de las ventas, de los costos incurridos, y las sumas pagadas a los trabajadores. Las agencias gubernamentales emplean la información contable para adoptar decisiones tributarias y normativas.

\section{Contabilidad Financiera}

Objetivo 5.- Identificar el propósito de los principios de contabilidad y auditoría generalmente aceptados.

Debido a la necesidad de información y a que la responsabilidad derivada de los conflictos de intereses (riesgo moral) les concierne, los administradores de empresas importantes preparan la información contable para su empleo por los inversionistas y otros usuarios externos de acuerdo a reglas específicas denominadas "principios de contabilidad generalmente aceptados". Dichos principios son normas desarrolladas por organizaciones profesionales de contabilidad para establecer procedimientos adecuados de contabilidad e información. Dichas normas establecen requisitos mínimos de declaración y facilitan la comparación de la información de un periodo y el siguiente, entre diferentes empresas.

Nota Instructiva.- Los "principios de contabilidad generalmente aceptados" se aplican sólo en la preparación de información para su empleo por quienes adoptan decisiones en el exterior. Debido a que los administradores controlan la información disponible dentro de la organización, dichos principios no son necesarios para su elaboración. 
La información contable proporcionada a los inversionistas de muchas corporaciones debe ser auditada. Una auditoría es el examen detallado de la información financiera de una empresa. Incluye el examen del sistema de información empleado en la preparación de los informes y de los procedimientos de control que la organización adopta para asegurar la exactitud de la información contable. El propósito de una auditoría es evaluar si la información proporcionada a quienes adoptan decisiones en el exterior refleja fielmente las actividades económicas de la empresa. Las normas para la preparación y emisión de la información ayudan a asegurar la confiabilidad de la información contable. Los auditores, que son contadores públicos calificados independientes, examinan la información para confirmar si está preparada conforme a las normas. Para ser contador público certificado se debe aprobar un examen de calificación y cumplir requisitos de capacitación y experiencia. Los contadores públicos certificados son independientes de las empresas que auditan, porque no son empleados de la compañía. Son contratados por los inversionistas y no deben tener intereses en la compañía que pudieran interferir su labor.

Objetivo 6.- Definir la contabilidad financiera.

La información contable preparada para su empleo por quienes adoptan decisiones en el exterior constituye información de contabilidad financiera. La contabilidad financiera es el proceso de preparar, emitir e interpretar la información contable proporcionada a quienes adoptan decisiones en el exterior. Como fuente principal de información para los inversionistas, es importante para las actividades financieras de las empresas. También influye en las decisiones de los proveedores, los clientes y los trabajadores.
Nota Instructiva.- Los administradores que adoptan decisiones en el interior de las empresas emplean la información de la contabilidad financiera, además de la proveniente de la contabilidad gerencial. Asimismo, se preocupan de los efectos de la información de la contabilidad financiera en las decisiones de los demás interesados.

Muchas corporaciones deben proporcionar la información proveniente de la contabilidad financiera auditada a las agencias gubemamentales. Las corporaciones cuyas acciones se comercian públicamente en Norteamérica deben informar a la Comisión de Bolsa y Valores. Esta agencia examina los informes financieros de las corporaciones para verificar su conformidad con los principios de contabilidad generalmente aceptados y con los requisitos de la Comisión de Bolsa y Valores. Una corporación cuyas acciones se cotizan en más de un país, debe informar a las autoridades de cada uno de esos países. Debido a que los diferentes países no emplean los mismos principios de contabilidad, podría ser necesario preparar informes separados para los inversionistas de los diferentes países. En Norteamérica, los bancos y otras instituciones financieras, las oficinas legales, los hospitales y muchas otras organizaciones también proporcionan información a las agencias gubernamentales.

\section{Contabilidad Gerencial}

Objetivo 7.- Definir la Contabilidad gerencial.

Los administradores necesitan información adicional a la proporcionada a quienes adoptan decisiones en el exterior, para evaluar la eficacia y eficiencia de las compañias.

La contabilidad gerencial (o de gerencia) es el procedimiento de preparar, emitir e interpretar la información contable para su empleo por 
quienes adoptan decisiones en el interior de una organización. Los administradores desarrollan sistemas de contabilidad de uso interno para satisfacer sus propias necesidades de información. Estos sistemas son distintos a los empleados en la emisión de información por la contabilidad financiera. La contabilidad gerencial es empleada por los administradores para planificar y controlar las decisiones.

Las decisiones de planificación exigen a los administradores señalar objetivos y desarrollar estrategias $y$ políticas para lograrlos. Estas decisiones incluyen qué bienes y servicios producirá la empresa, dónde colocará sus recursos, qué tecnología empleará y cómo incursionará en nuevos mercados. Estas decisiones determinan la estructura de una organización. Los administradores estiman la rentabilidad de estrategias alternativas y los riesgos asociados con la adopción de dichas alternativas.

Las decisiones de control exigen a los administradores evaluar el rendimiento de la organización y a efectuar modificaciones si la organización no está logrando sus objetivos. Verifican el cumplimiento de las políticas y estrategias desarrolladas durante el proceso de planificación. Asimismo, evalúan y estimulan al personal para alcanzar los objetivos de la empresa.

Las decisiones de planificación se orientan al futuro. ¿Qué ocurrirá en el futuro? Las decisiones de control se orientan al pasado y al presente. ¿Qué se ha logrado y qué cambios son necesarios para mejorar el rendimiento? Las decisiones de planificación son de largo plazo. ¿Cuáles son los objetivos para los próximos cinco años? Las decisiones de control son más inmediatas. ¿Se están logrando los objetivos? En caso contrario, ¿qué hacer para mejorar la situación?
Las decisiones de planificación y de control se adoptan en relación a las actividades de inversión y de operación. Los administradores planifican las necesidades de recursos financieros y cómo serán invertidos. Evalúan el empleo de los recursos y los resultados obtenidos. Planifican nuevos productos, su diseño y la adquisición de recursos para producirlos. Planifican la producción, distribución, mercadeo y servicio a los bienes. Las decisiones de control evalúan dichas actividades. El control de costos es la principal tarea de los administradores que influye en la eficiencia de la empresa.

\section{La contabilidad y las necesidades de información}

El sistema de información contable debería ser apropiado para proveer la información que la empresa necesita. Siempre se requieren sistemas especializados de contabilidad para satisfacer las diversas necesidades de información de los administradores, para informar a los inversionistas, para declarar y pagar impuestos, para informar a las diversas autoridades gubernamentales. Estos sistemas operan en conjunto para satisfacer los requerimientos de quienes deciden acerca de una empresa. Las decisiones de los administradores no son independientes de las que adoptan los inversionistas, los clientes, los proveedores, etc. La información emitida al exterior influye en las decisiones internas. La contabilidad financiera es una ventana que permite apreciar desde el exterior las consecuencias de las decisiones adoptadas por los administradores. Luego, las decisiones de los administradores constituyen el principal interés de la contabilidad financiera y la contabilidad gerencial.

La información contable se puede dividir en componentes de contabilidad financiera y contabilidad gerencial: 


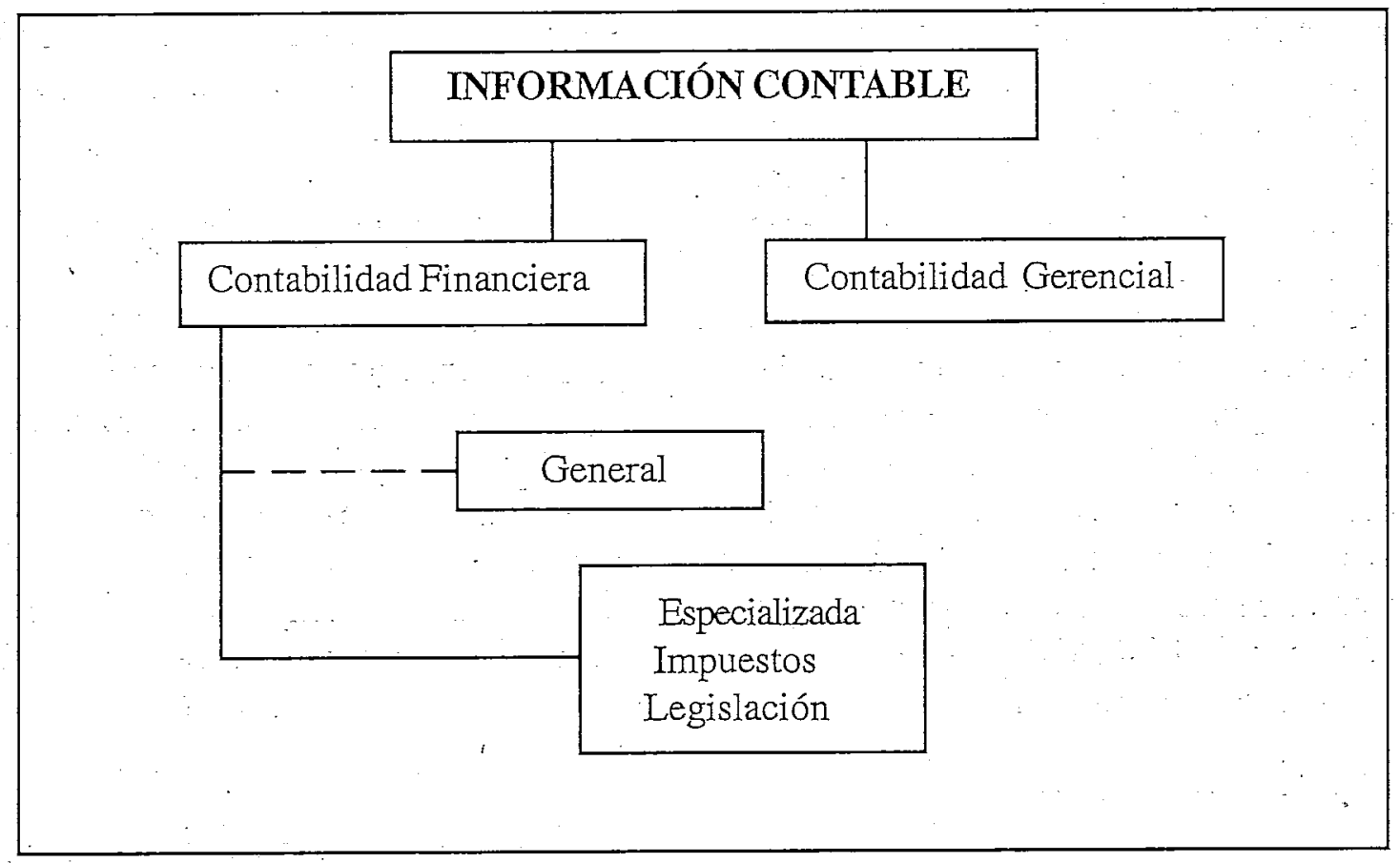

Caso Típico.- Suponga que Ud. es dueño de un negocio de revelado de películas fotográficas ubicado en un centro comercial y posee un equipo con capacidad para revelar 1000 rollos de películas al día. Por lo general, Ud. procesa 500 rollos diarios. Empleando sus decisiones de planificación Ud. desea hallar una estrategia para aumentar su producción y aprovechar su capacidad inactiva. Una estrategia podría consistir en abrir pequeñas tiendas en diferentes partes de la ciudad donde los clientes lleven sus películas. Dos veces al día, las películas serían transportadas al local del centro comercial. Luego de reveladas, se devolverían a la sucursal en el próximo viaje.

Dicha estrategia aumentaría el número de clientes, quienes no tendrían que llevar sus películas al centro comercial. También, su negocio sería conocido en diferentes partes de la ciudad. Aunque es buena estrategia, depende de la cantidad de trabajo adicional que Ud. podría efectuary del costo de abrir sucursales y transportar las películas.
La planificación depende de la comparación entre los beneficios relativos y los costos previsibles al adoptar la estrategia. El proceso de control adquiere importancia cuando Ud. se decide por una estrategia. El éxito depende de cómo cada sucursal cumpla su cometido. Debe evaluar cada sucursal que abra. ¿Logra buenos resultados? ¿Las películas son entregadas a tiempo? ¿ $\mathrm{Su}$ funcionamiento es costoso? ¿Cómo atienden los empleados a los clientes? Respondiendo estas interrogantes, Ud. puede optar por cerrar o trasladar ciertas sucursales o reemplazar determinado personal. Ud. puede decidir si la estrategia es satisfactoria y necesita aumentar sus operaciones. La planificación y el control trabajan juntos. Cuando planifica, Ud. decide qué hacer. Cuando controla, Ud. evalúa lo que ha hecho y decide las modificaciones para mejorar los resultados.

La contabilidad financiera comprende informes especializados y de carácter general, para quienes adoptan decisiones en el exterior. Los informes de carácter general se emiten para los inversionistas, los clientes, 
los trabajadores, etc., que necesitan información acerca del rendimiento global de una organización. Los informes especializados son preparados para las autoridades tributarias y normativas que requieren información específica que es preparada de acuerdo a reglas diferentes a las que se emplean para preparar los informes de carácter general. La contabilidad gerencial satisface variadas necesidades de información de quienes adoptan decisiones en el interior de una empresa. Esta información es emitida en una diversidad de formatos que pueden ser diseñados de acuerdo a las necesidades que surgen en una organización.

\section{Sistemas de información}

Objetivo 8.- Identificar las principales actividades en un sistema de información.

Para proveer la información requerida por los usuarios internos y externos, las empresas desarrollan sistemas para captar, procesar y emitir información. La Ilustración $\mathrm{N}^{\circ} 3$ muestra las principales actividades en un sistema de información.

Un sistema de información identifica y recoge datos de una fuente apropiada y los convierte en información utilizable para la adopción de decisiones. Los datos son hechos particulares o símbolos que pueden ser convertidos en información útil.

El propósito de un sistema de información podría ser convertir los datos para que sean más útiles antes de ser recibidos por los usuarios, o para lograr que la información sea más accesible. Por ejemplo, el sonido y las imágenes pueden ser convertidos por un micrófono y una cámara en señales almacenadas en discos compactos o en cintas. Al poner en acción los discos o las cintas en un equipo apropiado, las señales son convertidas en sonidos e imágenes. Los dispositivos de almacenamiento aumentan la utilidad de la información y la conservan hasta cuando sea necesaria.

Las computadoras son sistemas de información muy conocidos. Los datos ingresan por medio de un teclado a la unidad de procesamiento, que los convierte en signos que pueden ser mostrados en una pantalla o una impresora, o almacenados. Un aspecto importante de este tipo de sistema, es que los datos son transformados en información por la computadora que emplea programas para reconstituir, resumir o tabular los datos que a la salida constituyen información útil.

La habilidad de almacenar y manipular datos antes de la salida es una característica importante de muchos sistemas de información. Una parte importante que permite el almacenamiento y manipulación es la base de datos que es un ordenamiento físico o electrónico de datos que permite que sean manipulados y recuperados sistemáticamente. Los directorios telefónicos y los diccionarios son ejemplos típicos de bases de datos. Si Ud. necesita encontrar algún número telefónico, o el significado de una palabra, puede buscar en su base de datos, porque dicha información está almacenada en orden alfabético. Una base de datos contable podría estar constituida por un archivo de computadora que contiene información acerca de las cantidades que se adeuda a ciertos acreedores.

\section{Sistemas de información gerencial}

Objetivo 9.- Explicar el propósito de un sistema de información gerencial.

Los sistemas de información diseñados por los administradores son la fuente de información que se provee a los inversionistas, acreedores, autoridades gubernamentales, $y$ 


\section{ILUSTRACIÓN No 3}

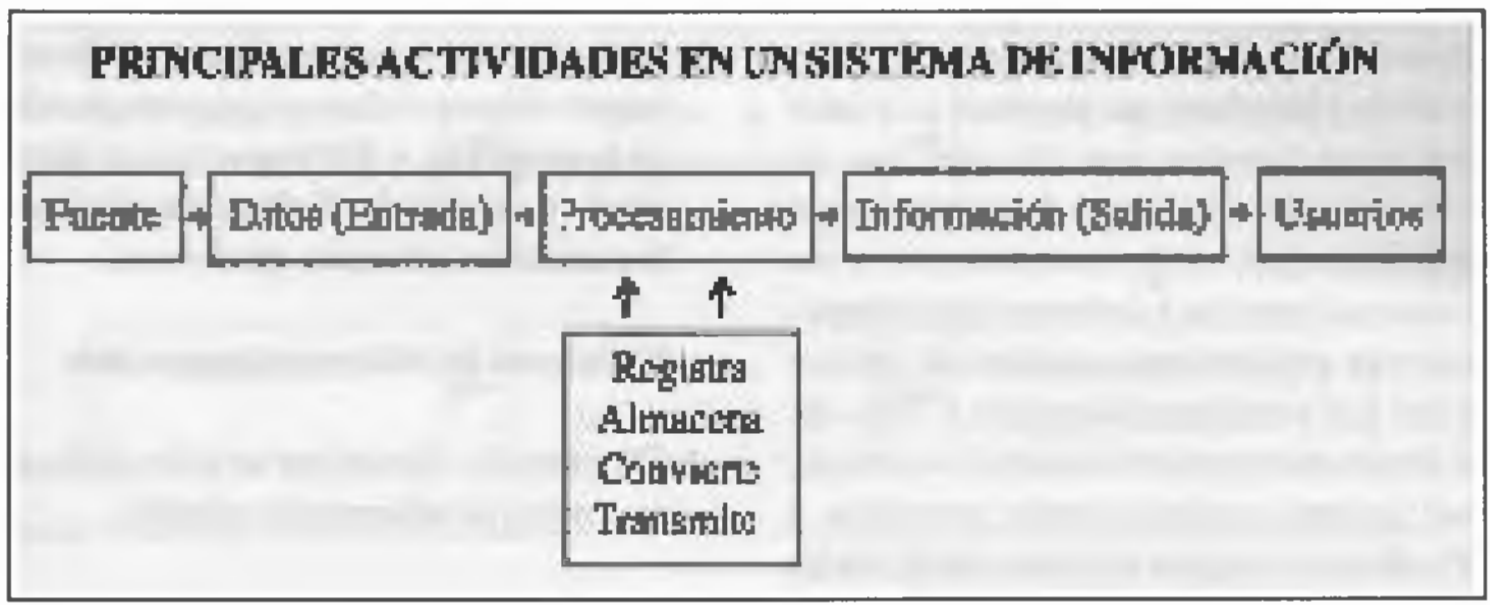

a quienes interactúan con los administradores. Un sistema de información gerencial proporciona la información que necesitan los administradores para la gestión de una empresa. En teoría, dicho sistema puede ser diseñado para captar información de todos los componentes de una organización, la cual es ordenada en una base de datos que provee información para adopción de decisiones por usuarios internos y externos. En realidad, no es frecuente encontrar tales sistemas en la mayoría de las organizaciones. Probablemente, la nueva tecnología los hará más comunes en el futuro cercano.

La Ilustración $\mathrm{N}^{\mathrm{o}} 4$ presenta un modelo comprensible de sistema de información gerencial, en el que cada componente de una organización provee entrada a la base de datos. Por ejemplo, Mercadeo proporciona datos del número de unidades y el importe de venta de cada tipo de producto en

\section{ILUSTRACIÓN $\mathrm{N}^{\circ} 4$}

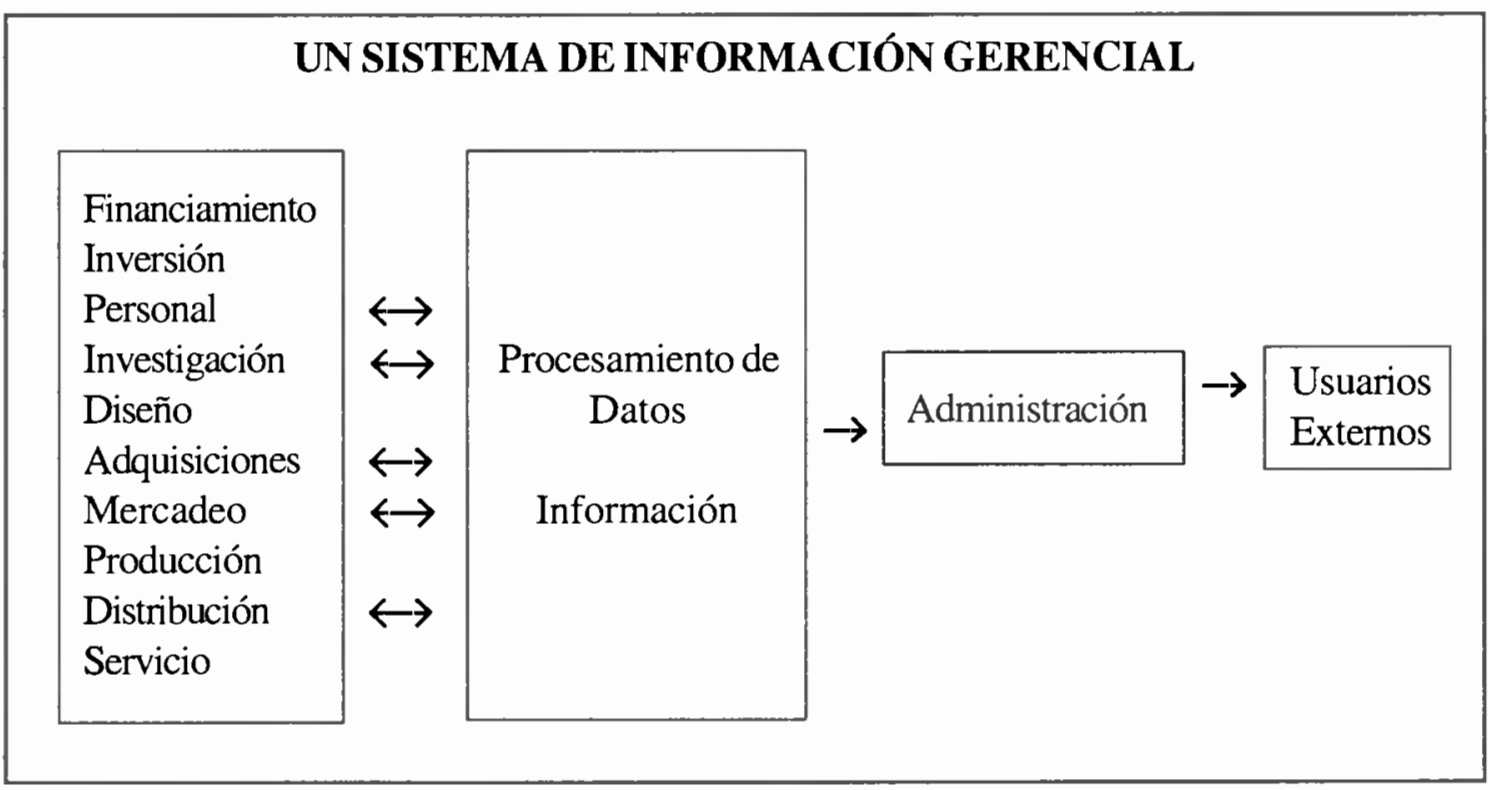


determinada localidad geográfica. Personal provee información del número de trabajadores de las diferentes divisiones y de los sueldos y beneficios que perciben. Los datos de estas fuentes son convertidos en información, en forma de programas e informes que son proporcionados a los usuarios internos y externos. Las computadoras proporcionan medios de enlace entre los administradores para el flujo de información entre las divisiones. Por ejemplo, un sistema computarizado permitiría a Producción averiguar el número de utilidades a producir para abastecer los pedidos; Adquisiciones podría determinar la cantidad de materiales a ordenar para los requerimientos de producción, etc.

Objetivo 10.- Explicar el propósito del sistema de información contable.

En lugar de un sistema central de información gerencial, las organizaciones suelen adoptar sistemas (o subsistemas) para fines diversos. Cada subsistema es parte del sistema central de información gerencial, por lo que pueden existir subsistencia para mercadeo, producción, personal, etc. Cada subsistema recoge datos de la etapa correspondiente del proceso de transformación, almacena y convierte los datos en información requerida por los gerentes de cada división. Periódicamente, la información es enviada a las demás divisiones o a la alta gerencia.

Sea como fuere, el sistema provee información acerca de los tipos, cantidades, ubicaciones y empleo de los recursos, desde el momento de su adquisición hasta que son consumidos, vendidos o desechados como parte del proceso de transformación.

El sistema de información contable, como subsistema específico, es responsable de: 1) Identificar los recursos de una organización, 2) Rastrear la trans- formación de recursos en bienes y servicios que son vendidos y entregados a los clientes o consumidores, 3) Determinar el costo de los recursos empleados en la empresa, y 4) Proporcionar información acerca de dichas actividades a los usuarios internos y externos.

\section{El sistema de información contable}

Objetivo 11. Identificar las actividades de un sistema de información contable.

Como los demás sistemas de información, el sistema contable es un proceso en el cual los datos ingresan, son registrados y almacenados en una base de datos, convertidos en números y tablas, y emitidos como programas, informes y otros tipos de información a los usuarios. Los principales datos del sistema contable son: 1) El costo de los recursos adquiridos y empleados en una organización. 2) Los precios de los bienes y servicios vendidos. 3) Las políticas administrativas que influyen en dichas actividades.

La Ilustración $\mathrm{N}^{\circ} 5$ muestra las actividades de un sistema de información contable.

La fuente de datos del sistema de información contable es el proceso de transformación de la empresa. Las actividades de financiamiento, de inversión y de operación son la fuente de datos de la organización, en relación a los recursos adquiridos, transformados y consumidos.

Los criterios de medición son normas que determinan las características del proceso de transformación que ingresan al sistema contable. Identifican los datos captados por el sistema. Por ejemplo, el sistema registra el costo pagado al adquirir equipo, pero no registra el precio al que se vendería, a menos que fuese vendido en el 


\section{ILUSTRACIÓN N ${ }^{\circ} 5$}

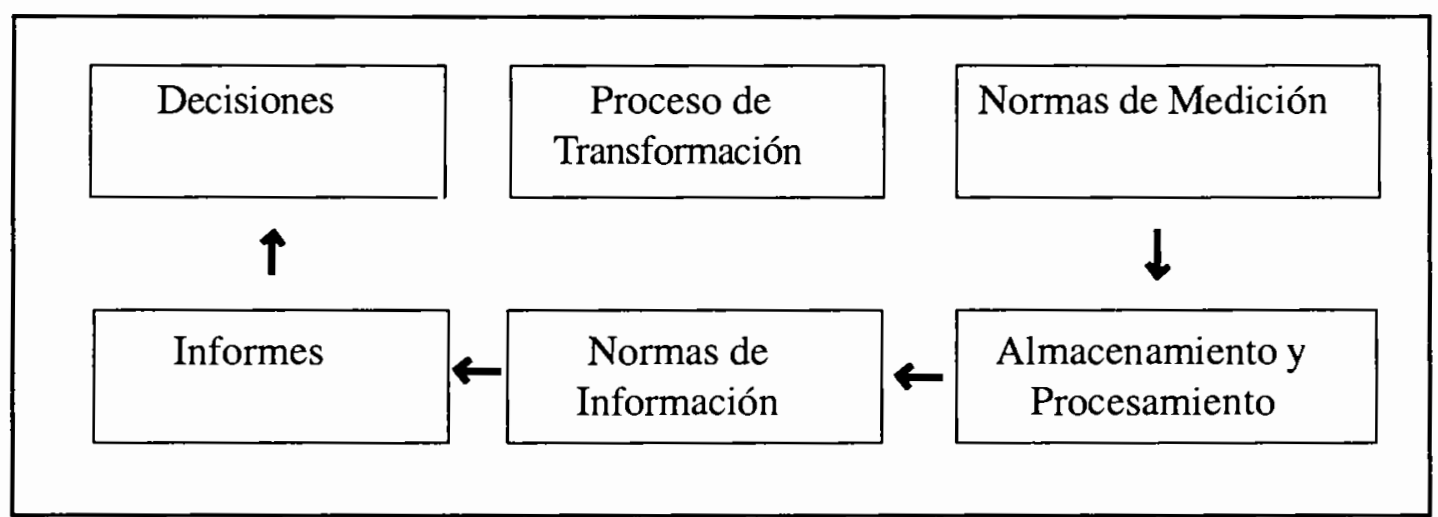

acto. En el sistema contable se registra el costo del equipo, pero no el tamaño, peso o color. Se adoptan normas de medición que seleccionan las características del proceso de transformación que son importantes para los usuarios. Los Principios de Contabilidad Generalmente Aceptados constituyen la principal fuente de normas de medición para la información de la contabilidad financiera de carácter general. Las autoridades gubernamentales determinan normas con requisitos tributarios y de control; y los administradores, sus propias normas de medición para la información de la contabilidad gerencial.

Las actividades del proceso de transformación medidas por el sistema contable son registradas en una o más fuentes de datos donde son almacenados y procesados. Las bases de datos de contabilidad son libros o archivos de computadoras que contienen cuentas donde son registradas, almacenadas y resumidas las transacciones de una empresa.

Cada transacción es registrada al ser identificadas las cuentas afectadas y el monto de la transacción. Suponga que una compañía adquirió equipo por $\$ 500$. Cada transacción se divide en dos partes, que identifican un intercambio entre la empresa y un cliente, proveedor, inversionista, etc. Por ejemplo, la compañía recibe equipo y entrega dinero.

El registro de una transacción es similar al de una cuenta de cheques. Se anota la fecha, el propósito y el monto de la transacción. La base de datos permite contabilizar y resumir de varias maneras. Una empresa puede determinar cuánto gastó en un periodo, en qué se empleó el dinero, qué recursos se adquirieron y cómo fueron empleados. Los usuarios pueden obtener de la base de datos los diferentes tipos de información según sus necesidades.

Las normas de información son criterios que determinan la información que emitirá el sistema de información. Determinan qué datos serán presentados para ciertos usos y el formato de la presentación. Algunos usuarios podrían necesitar información acerca de qué productos fueron vendidos, en qué cantidad, en qué lugares o periodos. Otros, podrían solicitar información general acerca del total de ventas de una compañía. Los Principios de Contabilidad Generalmente Aceptados proveen normas para la emisión de información de contabilidad gerencial de carácter general. Las autoridades gubernamentales establecen normas de información tributaria y de regulación, y los administradores determinan normas para la 
emisión de los informes de contabilidad gerencial.

Los informes proveen la información emitida por el sistema de contabilidad. Pueden ser obtenidos en varias formas, impresos en papel o presentados en la pantalla de una computadora. La frecuencia de los informes y la cantidad de datos que contienen dependerán de las necesidades de los usuarios.

Los usuarios adoptan decisiones después de evaluar la información emitida. Emplean normas de decisión para interpretar la información. Por ejemplo, un inversionista puede decidir si venderá las acciones que posee, si las utilidades declaradas por la compañía que las emitió disminuyen durante tres años consecutivos. Compara la información acerca de las utilidades con las normas de decisión y puede optar por vender o conservar sus acciones. Quienes adoptan decisiones emplean la información contable para evaluar el riesgo y la ganancia.

Una etapa importante del sistema descrito en la Ilustración $\mathrm{N}^{\circ} 5$ es el vínculo entre las decisiones y el proceso de transformación. Las decisiones de los usuarios afectan a la organización. Si los inversionistas deciden no adquirir las acciones de una compañía, o si los acreedores se rehusan a prestarle dinero, podrían tener dificultades para obtener recursos financieros para continuar operando, o podrían cerrar. Si los clientes tienen incertidumbre acerca de la continuidad de una compañía, podría decidir no adquirir sus productos. 